\title{
SECAGEM DE SEMENTES DE MARACUJÁ EM CAMADA DELGADA ${ }^{1}$
}

\author{
VINÍCIUS DE OLIVEIRA CARLESSO², PEDRO AMORIM BERBERT ${ }^{3}$, ROBERTO FERREIRA DA SILVA4, \\ ALEXANDRE PIO VIANNA ${ }^{5}$, EDENIO DETMANN ${ }^{6}$, RAFAEL GOMES DIONELLO ${ }^{7}$
}

\begin{abstract}
RESUMO - Utilizou-se do modelo matemático de secagem proposto por Page (1949) para se derivar uma equação de secagem em camada delgada para sementes de maracujá-amarelo (Passiflora edulis f. flavicarpa Degener.). Para a obtenção da equação, foram coletados dados experimentais em um protótipo de secador de leito fixo, utilizando-se de três níveis de temperatura do ar de secagem (30; 37 e $40^{\circ} \mathrm{C}$ ), três níveis de fluxo de ar para

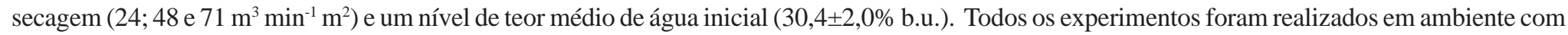
temperatura de $28,4 \pm 1,0^{\circ} \mathrm{C}$ e razão de umidade de $0,0138 \pm 0,0016 \mathrm{~kg} \mathrm{~kg}^{-1}$. Os valores dos resíduos obtidos com a equação desenvolvida por meio de análise de regressão não-linear foram considerados inadequadas para fins de engenharia, o que sugere a necessidade de avaliar outros modelos, teóricos ou empíricos, para a secagem de sementes de maracujá em camada delgada. Observou-se que o tempo de secagem diminuiu em função do aumento da temperatura; porém, não houve influência da vazão específica do ar de secagem sobre o tempo necessário para reduzir o teor de água de sementes de maracujá-amarelo para $9,9 \pm 0,4 \%$ b.u..
\end{abstract}

Termos para Indexação: Equação de Page, secagem de produtos agrícolas, maracujá.

\section{THIN-LAYER DRYING OF PASSION FRUIT SEEDS}

\begin{abstract}
The original mathematical drying model proposed by Page (1949) was used to derive a thin-layer drying equation to describe the drying of seeds of yellow passion fruit (Passiflora edulis L.). With this purpose, experimental drying data were collected using a fixed-bed prototype drier, using three levels of drying-air temperature $\left(30,37\right.$ e $\left.40^{\circ} \mathrm{C}\right)$; three levels of specific airflow rate $\left(24,48\right.$ e $\left.71 \mathrm{~m}^{3} \mathrm{~min}^{-1} \mathrm{~m}^{2}\right)$, and one level of initial moisture content (30.4 $\pm 2.0 \%$ w.b.). All tests were conducted in an Agricultural Engineering Laboratory where the average temperature and humidity ratio were $28.4 \pm 1.0^{\circ} \mathrm{C}$, and $0.0138 \pm 0.0016 \mathrm{~kg} \mathrm{~kg}^{-1}$, respectively. The values of errors produced by the equation derived by non-linear regression analyses were considered unacceptable for engineering purposes; this may suggest the need to evaluate other theoretical or empirical models to describe the thin-layer drying of yellow passion fruit seeds. Experimental data revealed, as expected, that as the drying air increased, the total time of drying decreased. Nonetheless, specific airflow rate appears to have no influence on drying time to reduce the initial moisture content of seeds of yellow passion fruit to a final value of $9.9 \pm 0.4 \%$ w.b.
\end{abstract}

Index terms: Page drying equation, drying of agricultural products, passion fruit.

\section{INTRODUÇÃO}

No âmbito do pré-processamento de sementes, a secagem é, sem dúvida, a operação unitária mais importante para se obter produto de ótima qualidade e dela depende a qualidade fisiológica do produto final a ser comercializado ou usado como meio de propagação do maracujazeiro. Esse tipo de produto apresenta, geralmente, altos valores de teor de água inicial que devem ser reduzidos com a secagem para que seja armazenado em condições seguras (Brooker et al., 1992). São poucos os dados disponíveis na literatura sobre o controle de processos durante a secagem de sementes de fruteiras, necessitando-se de estudos científicos mais aprofundados sobre a influência destes parâmetros na alteração da qualidade fisiológica das sementes destas espécies em geral, uma vez que estas apresentam potencial econômico para larga utilização no agronegócio em nosso País.

Em razão da crescente demanda por frutas exóticas no mercado internacional, a secagem artificial de sementes de fruteiras com comportamento ortodoxo no armazenamento vem sendo considerada um dos processos mais importantes no seu pré-processamento, visando a seu subseqüente beneficiamento industrial, estocagem ou sua comercialização. Os limites da temperatura do ar de secagem são determinados em função da sensibilidade dos componentes químicos que determinam a viabilidade da semente, uma vez que o produto, durante a secagem, em períodos à taxa decrescente, tem a sua temperatura aumentada, aproximando-se daquela na qual o processo se desenvolve. Outro fator relevante na qualidade fisiológica das sementes submetidas à secagem é a velocidade do ar usada no processo. Em algumas situações, uma vez aumentada a taxa de insuflação do ar através do produto, pode ocorrer aumento da taxa de água removida, ocasionando diminuição do tempo de secagem e alterações qualitativas no produto. Dessa forma, a combinação desses dois parâmetros irá interferir diretamente na taxa de secagem, podendo contribuir de forma significativa na diminuição do tempo gasto no processo, impedindo a degradação das sementes submetidas à secagem.

Sendo assim, é notória a necessidade de as instituições de pesquisa e de os produtores de frutas investirem em P\&D, principalmente na área de pré-processamento de sementes, para alcançar os padrões de qualidade exigidos pelo mercado internacional. Acreditase que a área de pré-processamento e armazenamento de sementes é a mais deficiente em informações científicas no âmbito do trabalho multidisciplinar que envolve $o$ assunto.

De acordo com Queiroz et al. (1985), são dois os métodos comumente usados para analisar a secagem de produtos biológicos no período de taxa decrescente: o empírico e o teórico. O método empírico consiste em formar grupos físicos adimensionais que podem ser facilmente investigados por experimentos de laboratório e baseia-se nas condições externas, como temperatura, umidade e velocidade do ar de secagem. Entretanto, não fornece indicação sobre o transporte de energia e de água no interior dos produtos. Expressões teóricas, semiteóricas e empíricas para a secagem de sementes de maracujá raramente são encontradas na literatura. As empíricas negligenciam os fundamentos do processo de secagem e, embora possam descrever a curva de secagem para as condições do experimento, não podem dar uma visão clara e exata dos importantes processos que ocorrem durante a secagem. Os métodos teóricos usados para descrever o processo de secagem, são baseados em leis físicas que tentam explicar o mecanismo

\footnotetext{
${ }^{1}$ (Trabalho 151/2004). Recebido: 04/11/2004. Aceito para publicação: 21/09/2005.

${ }^{2}$ MS, Produção Vegetal, Laboratório de Engenharia Agrícola, UENF, Campos dos Goytacazes - RJ, vcarlesso@bol.com.br.

${ }^{3}$ Ph.D., Professor Associado, Laboratório de Engenharia Agrícola, UENF, Campos dos Goytacazes - RJ, E-Mail: pberbert@uenf.br.

${ }^{4}$ Ph.D., Professor Titular, Laboratório de Fitotecnia, UENF, Campos dos Goytacazes - RJ, E-Mail: roberto@uenf.br.

${ }^{5}$ D.S., Professor Associado, Lab. de Melhoramento Genético Vegetal, UENF, Campos dos Goytacazes - RJ, E-Mail: pirapora@uenf.br.

${ }^{6}$ D.S., Professor Adjunto, Departamento de Zootecnia, UFV, Viçosa - MG, E-mail: detmann@ufv.br.

${ }^{7}$ M.S., Doutorando, Programa de Pós-graduação em Produção Vegetal, UENF, Campos dos Goytacazes - RJ
} 
de transferência de água.

Os modelos que empregam a teoria da difusão, podem descrever de forma aceitável o perfil da distribuição de água no interior de determinado produto agrícola desde que seja possível correlacionar sua forma à geometria de um sólido perfeito, além da exigência do estabelecimento de uma relação funcional entre o coeficiente de difusão, o teor de água e a temperatura. Nesse caso, há que se considerar que o valor médio da razão de umidade (RU), quer seja determinado pela solução de uma série truncada quer seja por integração de um conjunto de pontos discretos, distribuídos na matriz do produto, representa a taxa de secagem de um sólido isolado, seja no formato de placa plana, cilíndrico, seja esférico (Crank, 1975). Esse tipo de solução deverá ser incorporado a um modelo de simulação de secagem em camada espessa para que seja possível prever a taxa de secagem de um lote de sementes, e não apenas de uma unidade isolada. Sendo assim, as soluções de modelos matemáticos difusivos requerem longo tempo computacional quando se compara com aquele gasto para solucionar a taxa de secagem de apenas uma unidade do produto; devido a isso e à dificuldade inerente de estabelecer uma relação funcional do tipo $D=\mathrm{F}\left(\hat{U} ; \theta_{a b s}\right)$, em que $\mathrm{D}=$ coeficiente de difusão $\left(\mathrm{m}^{2} \mathrm{~s}^{-1}\right), \hat{\mathrm{U}}=$ teor médio de água (\% b.u.) e $\theta_{a b s}=$ temperatura absoluta, para diversas classes de produtos, muitos pesquisadores têm preferido utilizar equações empíricas de secagem (Parry, 1985).

Modelos empíricos de secagem em camada delgada seriam aqueles que concorreriam para que houvesse harmonia entre a teoria e a facilidade de uso. A secagem em camada delgada refere-se ao processo no qual o material a ser seco está inteiramente exposto ao ar que se move através dele (Queiroz et al., 1985). A equação que representa o movimento de líquido ou vapor em uma camada fina do produto durante o período de secagem à taxa decrescente, é obtida utilizando-se da Lei de Newton para o aquecimento e o resfriamento, ou seja, a taxa de variação da temperatura de um corpo circundado por um fluido à temperatura constante é proporcional à diferença de temperatura entre eles, desde que essa diferença seja pequena (Hall, 1980).

$\frac{d \theta}{d t}=-\xi\left(\theta-\theta_{e}\right)$

$\xi=$ constante de resfriamento ou aquecimento;

$\theta=$ temperatura do produto em qualquer tempo $\mathrm{t}, \mathrm{e}$

$\theta_{e}=$ temperatura do meio que envolve o produto.

A Equação 1 é uma equação diferencial linear de primeira ordem, cuja solução pode ser obtida por separação de variáveis e posterior integração, resultando na equação exponencial mostrada a seguir (Equação 3).

$\int_{\theta_{0}}^{\theta} \frac{d \theta}{\left(\theta-\theta_{e}\right)}=\int_{t_{0}}^{t}-\xi d t$

$\frac{\theta-\theta_{e}}{\theta_{0}-\theta_{e}}=e^{-\xi t}$

Lewis (1921), citado por Hall \& Rodriguez-Arias (1958), obteve a seguinte equação diferencial ao verificar que a taxa de perda de água de um grão envolto em uma massa de ar é proporcional à diferença entre o teor de água do grão e o seu teor de água de equilíbrio.

$\frac{d \bar{U}}{d t}=k\left(\bar{U}-U_{e}\right)$
Por separação de variáveis e posterior integração, considerando-se as condições iniciais e de contorno apropriadas para uma equação de difusão, obteve-se a seguinte equação geral de secagem em camada delgada:

$\ln \left(\frac{\bar{U}_{t}-U_{e}}{U_{0}-U_{e}}\right)=-k t$

$\mathrm{ou}$

$\frac{\bar{U}_{t}-U_{e}}{U_{0}-U_{e}}=\exp (-k t)$

em que:

$k=$ constante de proporcionalidade ou constante de secagem, $\mathrm{s}^{-1}$

$\hat{U}_{t} \quad=$ teor médio de água em qualquer instante $\mathrm{t}$, decimal b.s.;

$U_{e}=$ teor de água na condição de equilíbrio, decimal b.s., e

$U_{0}^{e} \quad=$ teor de água inicial, decimal b.s.

Observando-se as Equações 1 e 6, é possível verificar a analogia entre as equações que representam a Lei de Newton para o resfriamento e a Equação de Lewis para a difusão, respectivamente. Devido à razoável aproximação entre os valores medidos e calculados pela Equação 6, também conhecida como Lei Exponencial ou Modelo Logaritmo de secagem, passou-se a considerá-la como uma equação que descrevia de forma aceitável os fenômenos de transferência de calor e massa durante a secagem de uma camada delgada de determinado produto capilar poroso.

De acordo com Parry (1985), apesar de a Equação 6 haver sido deduzida a partir da teoria da difusão, considerou-se que a resistência à transferência de massa ocorresse principalmente numa camada delgada superficial do produto, o que nem sempre ocorre. Brooker et al. (1992) afirmam que o modelo exponencial emula de forma pouco satisfatória a curva de secagem; que o modelo prediz valores muito reduzidos para a taxa inicial de secagem e que o valor limite, ou seja, o teor de água de equilíbrio, é alcançado muito rapidamente, o que não condiz com as observações experimentais.

Page (1949), ao avaliar os fatores com influência significativa sobre a taxa máxima de secagem convectiva de sementes de milho em camada delgada e ao comparar os resultados obtidos experimentalmente com aqueles obtidos com o modelo exponencial, propôs a seguinte equação de secagem:

$\frac{\bar{U}_{t}-U_{e}}{U_{0}-U_{e}}=\exp \left(-k^{\prime} t^{\zeta}\right)$

em que:

$k^{\prime} \quad=$ constante modificada de secagem, expressa em tempo de meia-resposta;

$\zeta=$ constante que depende da umidade relativa e temperatura do ar de secagem;

$\hat{U}_{t} \quad=\quad$ teor médio de água em qualquer instante t, decimal b.s.;

$U_{e} \quad=$ teor de água na condição de equilíbrio, decimal b.s., e

$U_{0}^{e} \quad=$ teor de água inicial, decimal b.s.

O objetivo do trabalho foi determinar as curvas de secagem de sementes de maracujá-amarelo utilizando um secador de camada delgada com fluxo de ar ascendente e ajustar a equação de Page aos dados experimentais.

\section{MATERIALEMÉTODOS}

Os experimentos de secagem foram realizados no Laboratório de Engenharia Agrícola - LEAG, Centro de Ciências e Tecnologias 
Agropecuárias - CCTA, Universidade Estadual do Norte Fluminense Darcy Ribeiro (UENF), Município de Campos dos Goytacazes-RJ.

Utilizou-se de sementes de maracujá-amarelo provenientes da Fábrica Bela Joana Frutas e Sucos, do Grupo MPE, localizada na divisa dos municípios Campos dos Goytacazes e São Fidélis - RJ. As sementes, ao chegarem ao laboratório, foram colocadas para fermentar em meio aquoso, em recipiente de vidro, por 48 h. Após este período, foram lavadas em água corrente com o auxílio de uma peneira, retirando-se todo arilo e impurezas. Em seguida, secavam-se as sementes com papel toalha por cerca de $1 / 2 \mathrm{~h}$, visando à retirada do excesso de água superficial. As sementes foram então armazenadas em frascos de vidro com tampas rosqueadas e vedados com Parafilm ${ }^{\circledR}$, e acondicionadas em câmara do tipo B.O.D. à temperatura de $4^{\circ} \mathrm{C}$, de onde eram retiradas as amostras para os testes experimentais de secagem.

A determinação do teor de água inicial das sementes foi feita de acordo com as recomendações das Regras para Análise de Sementes (Brasil, 1992), em estufa com convecção forçada a $130^{\circ} \mathrm{C}$, por $1 \mathrm{~h}$, em triplicata. Os experimentos de secagem em camada fina foram realizados utilizando-se de um protótipo de secador de leito fixo (Figura 1), fabricado pela Indústria e Comércio de Máquinas Polidryer Ltda, localizada em Viçosa-MG. O secador foi construído em paredes duplas, com inserção de material isolante térmico entre as chapas. A câmara de secagem é constituída por uma bandeja circular com fundo em chapa perfurada de aço inoxidável, com diâmetro interno de 0,25 m e altura de 0,10 m (Figura 2). A regulagem do fluxo de ar foi feita utilizando-se de um diafragma com aberturas reguláveis e localizado no duto de entrada de um ventilador centrífugo de 1,0 cv (Figura 3). Foram analisados três níveis de temperatura do ar de secagem, $30 ; 37$ e $40^{\circ} \mathrm{C}$; três níveis de velocidade do ar, 0,4; 0,8 e 1,2 $\mathrm{m} \mathrm{s}^{-1}$ e apenas um nível médio de teor de água inicial, $\hat{\mathrm{U}}_{\mathrm{i}}=30,4 \pm 2,0 \%$ b.u. O aquecimento do ar foi feito por meio de um conjunto de resistências elétricas com potência total de $5 \mathrm{~kW}$. O delineamento experimental foi inteiramente casualizado, composto de 9 tratamentos, com três repetições para cada tratamento, num total de 27 parcelas experimentais.

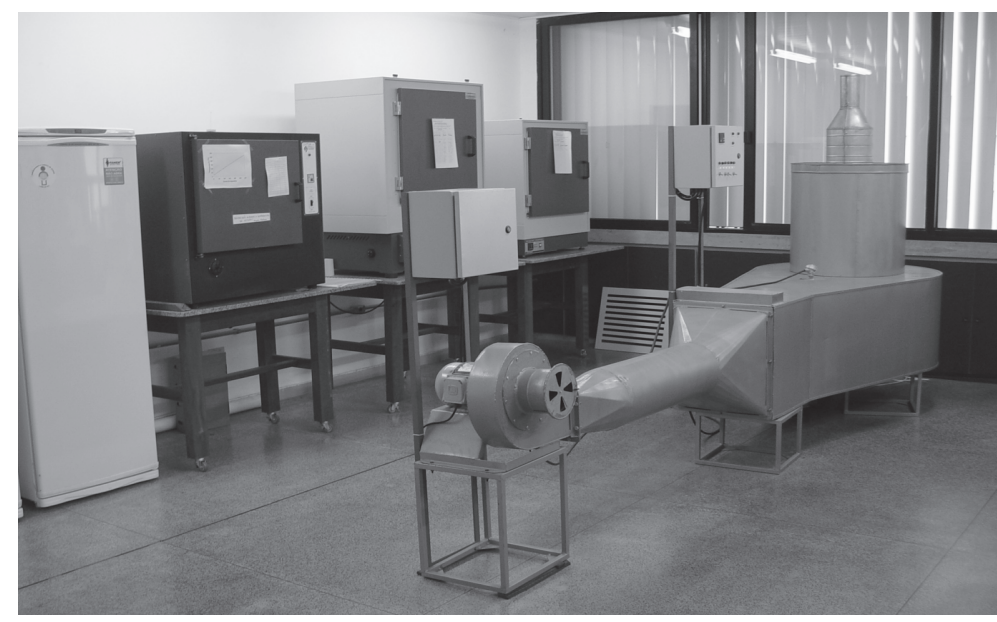

FIGURA 1 - Secador experimental de leito fixo.

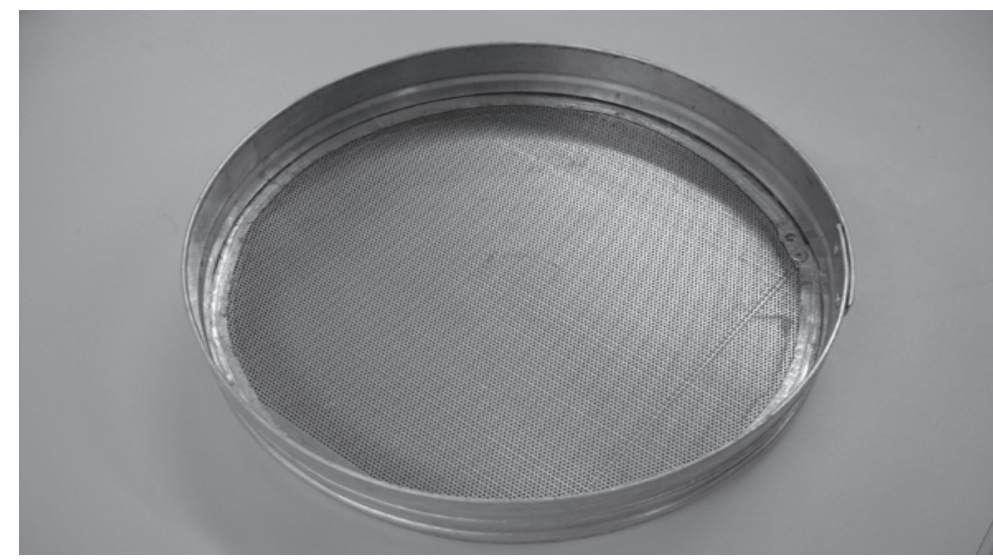

FIGURA 2 - Bandeja circular com fundo de chapa de aço inox perfurada, de diâmetro interno igual a 0,25 m e altura de $0,10 \mathrm{~m}$.

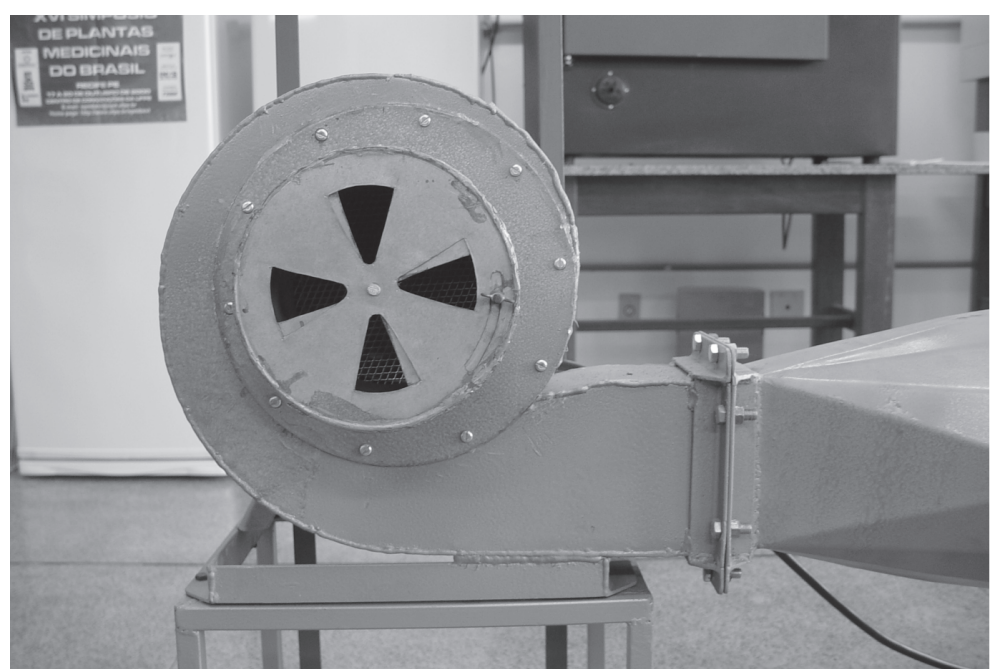

FIGURA 3 - Diafragma regulável, localizado na entrada do ventilador.

A temperatura do ar de secagem foi medida utilizando-se de termômetro ordinário de mercúrio, com divisão de escala de $1^{\circ} \mathrm{C}$, sendo posicionado logo abaixo da câmara de secagem. O controle da temperatura foi feito por um controlador microprocessado $\mathrm{N} 480$, com precisão de 0,2\% da faixa máxima, para sensores tipo Pt 100 e 0,25\% \pm $1^{\circ} \mathrm{C}$ para termopares. A velocidade do ar de secagem foi medida utilizando-se de um anemômetro de pás rotativas Airflow ${ }^{\circledR}$ Modelo AV6, posicionado na saída de um dispositivo metálico localizado no topo da câmara de secagem (Figura 1). As leituras de velocidade e temperatura foram registradas imediatamente antes de cada pesagem. A temperatura e a umidade relativa do ar ambiente foram medidas com aparelho digital Hygrometer - Series 485, fabricado pela Dwyer Instrumentas, Inc. A intenção deste monitoramento foi avaliar as demais propriedades psicrométricas do ar de secagem, como entalpia, razão de mistura, volume específico, etc, propiciando a caracterização dos experimentos, utilizando as equações propostas por Wilhem (1976). O secador contém, ainda, um inversor de freqüência para a regulagem da velocidade de rotação do motor que aciona o ventilador.

A quantidade de água removida durante o processo de secagem foi determinada por processo gravimétrico, com auxílio de balança semianalítica. As pesagens foram feitas a cada 5 min na primeira meia-hora, a cada 10 min até $120 \mathrm{~min}$, a cada 15 min até 180 min e a cada 30 min a partir de $180 \mathrm{~min}$. A secagem foi interrompida quando o teor de água do produto atingia o valor de $10 \%$ b.u.

Na análise estatística dos dados, procedeu-se ao ajustamento das variáveis razão de mistura e tempo de secagem, por intermédio do procedimento de Gauss Newton (Souza, 1998), implementado sobre o programa SAEG (Sistemas de Análises Estatísticas), do modelo nãolinear descrito pela Equação 7. A avaliação da adequação do modelo empregado para a descrição do fenômeno estudado foi realizada por intermédio da avaliação do coeficiente de determinação, estimado como o quadrado do coeficiente de correlação linear entre valores preditos e observados para a variável dependente razão de umidade $\left[\left(\hat{U}_{t}-U_{f}\right) /\left(U_{0}-\right.\right.$ $\left.\mathrm{U}_{\mathrm{f}}\right)$ ] (Souza, 1998); por intermédio dos intervalos de confiança assintóticos para os parâmetros de ajustamento $(1-\alpha=0,95)$, e através da avaliação gráfica dos resíduos padronizados (Draper \& Smith, 1966).

\section{RESULTADOS E DISCUSSÃO}

Os valores médios de temperatura e a razão da mistura do ar ambiente, as condições iniciais do produto, os parâmetros de secagem utilizados nos testes experimentais e seus resultados, para temperaturas do ar de secagem de $30 ; 37$ e $40^{\circ} \mathrm{C}$, encontram-se na Tabela 1 . O tempo de secagem diminuiu em função do aumento da temperatura e mantevese praticamente constante em relação às variações na velocidade do ar de secagem entre 0,4 e $1,2 \mathrm{~m} \mathrm{~s}^{-1}$.

A equação que melhor se ajustou ao conjunto de valores de razão de umidade e tempo de secagem, $t$, segundo o modelo proposto por 
TABELA 1 - Condições médias do ar e da semente para as temperaturas de 30; 37 e $40^{\circ} \mathrm{C}$ e tempo de secagem

\begin{tabular}{|c|c|c|c|c|c|c|c|c|c|}
\hline Teste & 1 & 2 & 3 & 4 & 5 & 6 & 7 & 8 & 9 \\
\hline \multicolumn{10}{|l|}{ Condições do ar ambiente: } \\
\hline Temperatura,${ }^{\circ} \mathrm{C}$ & 26,6 & 28,6 & 28,1 & 28,8 & 29,0 & 27,8 & 28,6 & 29,0 & 29,0 \\
\hline Razão da mistura, $\mathrm{kg} \mathrm{kg}^{-1}$ & 0,0120 & 0,0137 & 0,0146 & 0,0108 & 0,0130 & 0,0142 & 0,0148 & 0,0160 & 0,0141 \\
\hline \multicolumn{10}{|l|}{ Condições de secagem: } \\
\hline Temperatura, ${ }^{\circ} \mathrm{C}$ & 30,0 & 30,9 & 31,4 & 37,6 & 37,1 & 37,1 & 40,0 & 39,9 & 39,9 \\
\hline Velocidade do ar, $\mathrm{m} \mathrm{s}^{-1}$ & 0,4 & 0,8 & 1,2 & 0,4 & 0,8 & 1,2 & 0,4 & 0,8 & 1,2 \\
\hline Fluxo ar seco, $\mathrm{kg} \mathrm{s}^{-1} \mathrm{~m}^{-2}$ & 0,51 & 0,93 & 1,37 & 0,47 & 0,93 & 1,38 & 0,46 & 0,93 & 1,37 \\
\hline Vazão, $\mathrm{m}^{3} \min ^{-1} \mathrm{~m}^{-2}$ & 26,1 & 48,1 & 70,4 & 24,1 & 47,9 & 71,4 & 23,9 & 48,0 & 70,9 \\
\hline \multicolumn{10}{|l|}{ Condições iniciais do produto: } \\
\hline Temperatura,${ }^{\circ} \mathrm{C}$ & 26,5 & 28,6 & 28,0 & 28,8 & 29,0 & 27,9 & 28,4 & 28,7 & 28,9 \\
\hline Teor de água, \% b.u. & 27,8 & 28,9 & 29,9 & 33,2 & 30,0 & 33,7 & 30,3 & 30,4 & 30,2 \\
\hline \multicolumn{10}{|l|}{ Condições finais do produto: } \\
\hline Teor de água, \% b.u. & 9,9 & 9,9 & 10,1 & 9,8 & 9,1 & 9,9 & 10,0 & 9,9 & 9,8 \\
\hline Teтpo, $h$ & 0,80 & 0,79 & 0,88 & 0,67 & 1,00 & 0,66 & 0,50 & 0,50 & 0,50 \\
\hline
\end{tabular}

Page (1949) e para as condições avaliadas nesse trabalho. A Equação 8, $\mathrm{R}^{2}=0,86$, foi obtida de acordo com os procedimentos descritos anteriormente; o resumo da análise estatística é apresentado na Tabela 2.

TABELA 2 - Parâmetros estatísticos relativos à análise de regressão não-linear resultantes do ajuste dos dados experimentais de secagem de sementes de maracujá-amarelo ao modelo de Page (1949).

\begin{tabular}{ccccc}
\hline Parâmetro & $\begin{array}{c}\text { Estimativa } \\
\text { do } \\
\text { parâmetro }\end{array}$ & $\begin{array}{c}\text { Desvio- } \\
\text { padrão da } \\
\text { estimativa }\end{array}$ & \multicolumn{2}{c}{$\begin{array}{c}\text { Limites do intervalo } \\
\text { de confiança } \\
\text { assintótico }(95 \%)\end{array}$} \\
\hline$k$ & 4,5212 & 0,1449 & 4,2360 & 4,8063 \\
$\zeta$ & 0,6525 & 0,0185 & 0,6161 & 0,6889 \\
\hline
\end{tabular}

$\frac{\bar{U}_{t}-U_{e}}{U_{0}-U_{e}}=\exp \left(-4,5212 t^{0,6525}\right)$

Na Figura 4, vê-se o gráfico de correspondência entre os valores de razão de umidade, experimentais e estimados pela Equação 8, para todas as condições de secagem estudadas neste trabalho. Notase que o modelo de Page (1949) superestima os valores de RU em praticamente todo o período de secagem de sementes de maracujáamarelo; quando RU tende a zero, os valores estimados e experimentais voltam a se aproximar. Esse comportamento torna-se mais visível quando se analisa a Figura 5, que mostra o gráfico dos resíduos.

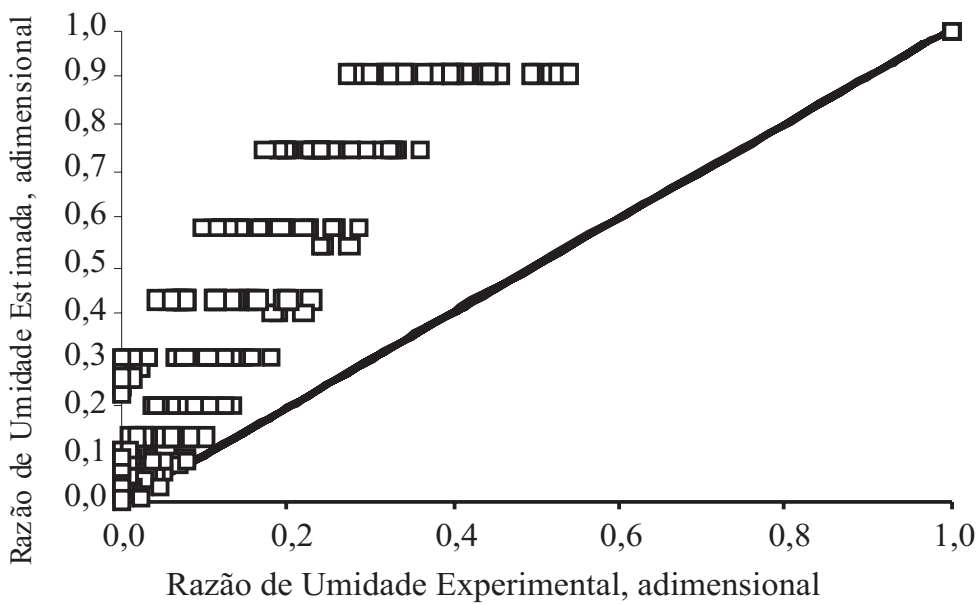

FIGURA 4 - Gráfico de Correspondência entre os valores de razão de umidade, experimentais e calculados de acordo com a Equação 8, para secagem de sementes de maracujá-amarelo a $30 ; 37$ e $40^{\circ} \mathrm{C}$

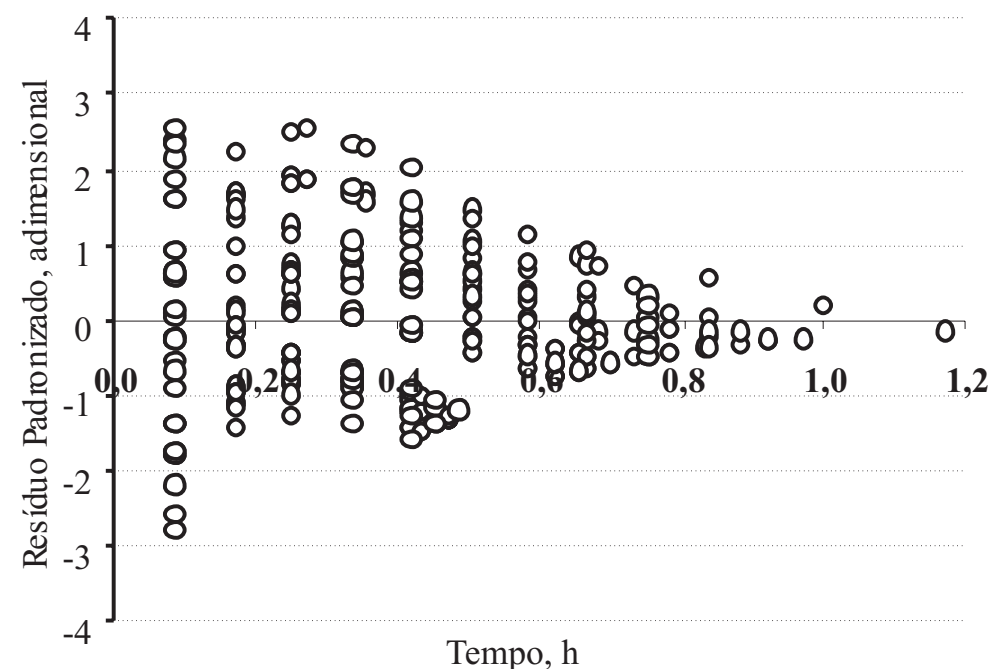

FIGURA 5 - Gráfico dos resíduos padronizados em função do tempo, para secagem de sementes de maracujá-amarelo a 30; 37 e $40^{\circ} \mathrm{C}$.

A análise dos dados apresentados na Figura 5 mostra um afunilamento dos valores dos resíduos entre os períodos inicial e final de secagem, ou seja, não houve uma distribuição ideal dos resíduos ao redor do valor zero. Na Figura 4, se o modelo representasse os valores experimentais com a devida acurácia, os resíduos estariam distribuídos aleatoriamente ao redor da linha contínua que representa a correspondência ideal entre os valores experimentais e estimados de RU.

De acordo com Parry (1985), apesar de a Equação 8 haver sido deduzida a partir da teoria da difusão, considerou-se que a resistência à transferência de massa ocorresse principalmente numa camada delgada superficial do produto, o que nem sempre ocorre. Para sementes de trigo, McEwen et al. (1954) interpretaram essa camada fina como sendo a camada aleurônica da semente, localizada entre seu pericarpo e o endosperma. No entanto, Babbitt (1949) já havia demonstrado que a camada muito mais espessa do endosperma é o fator limitante para a difusão. Além disso, Brooker et al. (1992) afirmam que o modelo exponencial emula de forma pouco satisfatória a curva de secagem; que o modelo prediz valores muito reduzidos para a taxa inicial de secagem e que o valor-limite, ou seja, o teor de água de equilíbrio, é alcançado muito rapidamente, o que não condiz com as observações experimentais. No caso do presente experimento, pode-se também afirmar que o modelo de Page (1949) resulta em valores de RU que não podem ser considerados aceitáveis para fins de engenharia; e também que prediz valores muito reduzidos de taxa de secagem no período inicial do processo, de acordo com o comportamento também observado por Brooker et al. (1992) para o modelo exponencial (Equação 6). 


\section{CONCLUSÕES}

De acordo com os resultados obtidos e para as condições em que foi desenvolvida esta pesquisa, conclui-se que:

1. A equação de secagem obtida a partir do modelo proposto por Page (1949) para secagem de produtos agrícolas granulares não se ajustou com o grau de acurácia desejado para fins de engenharia, às curvas experimentais de secagem de sementes de maracujá-amarelo.

2. O tempo de secagem diminuiu em função do aumento da temperatura; porém, não houve influência da vazão específica do ar de secagem sobre o tempo necessário para reduzir o teor de umidade de sementes de maracujá-amarelo de $\hat{U}_{i}=30,4 \pm 2,0 \%$ b.u. para $\hat{U}_{f}=9,9 \pm 0,4 \%$ b.u.

\section{AGRADECIMENTOS}

Os autores agradecem às Fundações de Amparo à Pesquisa dos Estados do Rio de Janeiro (FAPERJ) e Minas Gerais (FAPEMIG), à International Foundation for Science (IFS) e ao CNPq, pelo apoio financeiro. Agradecem também à Sra. Louise Dulce Ulup Andersen, pelo apoio aos projetos gráficos elaborados para essa linha de pesquisa.

\section{REFERÊNCIAS}

BABBITT, J. D. Observations on the adsorption of water vapor by wheat. Canadian Journal of Research, v.27F, p:55-72, 1949.

BRASIL. Regras para Análise de Sementes Brasília: Ministério da Agricultura e Reforma Agrária. Secretaria Nacional de Defesa Agropecuária. Departamento Nacional de Defesa Vegetal. Coordenação de Laboratório Vegetal, 1992. 365p.

BROOKER, D.B.; BAKKER-ARKEMA, F.W.; HALL, C.W. Drying and storage of grains and oilseeds. New York: Van Nostrand Reinhold, 1992.450p.
CRANK, J. The Mathematics of Diffusion. 2. ed. Oxford: Clarendon Press, 1975. 414p.

DRAPER, N.R.; SMITH, H. Applied regression analysis. New York: Jonh Willey \& Sons, 1966. 407p.

HALL, C.W. Drying and storage of agricultural crops. Westport: AVI Publishing Company, Inc., 1980. 382p.

HALL, C.W.; RODRIGUEZ-ARIAS, J.H. Equilibrium moisture content of shelled corn. Agricultural Engineering, v.39, n.8, p.466-470. 1958.

McEWEN, E.; SIMMONDS, W.H.C.; WARD, G.T. The drying of wheat grain. Part III: Interpretation in terms of its biological structure. Transactions of the Institution of Chemical Engineers, v.32, n.2, p.116-120. 1954.

PAGE, C. Factors Influencing the Maximum Rate of Drying Shelled Corn in Layers. West Lafayette, 1949. MSc Thesis, Purdue University.

PARRY, J.L. Mathematical modelling and computer simulation of heat and mass transfer in agricultural grain drying: A review. Journal of Agricultural Engineering Research, v.32, p.1-29. 1985

QUEIROZ, D.M.; PEREIRA, J.A.M.; MELO, E.C. Modelos Matemáticos de Simulação de Secagem de Grãos. Viçosa: Centro Nacional de Treinamento em Armazenagem, 1985. 59p.

SAEG. Sistema para Análises Estatísticas. Versão 8.0. Viçosa: FUNARBE, 2003

SOUZA, G.S. Introdução aos modelos de regressão linear e não-linear. Brasília: EMBRAPA-SPI, 1998. 505p.

WILHEM, L.R. Numerical calculation of psychrometric properties in SI units. Transactions of the American Society of Agricultural Engineers, St Joseph, v.19, n.2, p.318-321,325. 1976. 